\title{
Addison's disease in antiphospholipid syndrome: a rare complication
}

\author{
Diana Oliveira*, Mara Ventura*, Miguel Melo, Sandra Paiva and Francisco Carrilho \\ Endocrinology, Diabetes and Metabolism Department, Centro Hospitalar e Universitario de Coimbra EPE, \\ Coimbra, Portugal \\ *(D Oliveira and M Ventura contributed equally to this work)
}

Correspondence

should be addressed

to M Ventura

Email

maracventura@gmail.com

\section{Summary}

Addison's disease (AD) is the most common endocrine manifestation of antiphospholipid syndrome (APS), but it remains a very rare complication of the syndrome. It is caused by adrenal venous thrombosis and consequent hemorrhagic infarction or by spontaneous (without thrombosis) adrenal hemorrhage, usually occurring after surgery or anticoagulant therapy. We present a clinical case of a 36-year-old female patient with a previous diagnosis of APS. She presented with multiple thrombotic events, including spontaneous abortions. During evaluation by the third episode of abortion, a CT imaging revealed an adrenal hematoma, but the patient was discharged without further investigation. A few weeks later, she presented in the emergency department with manifestations suggestive of adrenal insufficiency. Based on that assumption, she started therapy with glucocorticoids, with significant clinical improvement. After stabilization, additional investigation confirmed AD and excluded other etiologies; she also started mineralocorticoid replacement. This case illustrates a rare complication of APS that, if misdiagnosed, may be life threatening. A high index of suspicion is necessary for its diagnosis, and prompt treatment is crucial to reduce the morbidity and mortality potentially associated.

\section{Learning points:}

- $A D$ is a rare but life-threatening complication of APS.

- It is important to look for AD in patients with APS and a suggestive clinical scenario.

- APS must be excluded in patients with primary adrenal insufficiency and adrenal imaging revealing thrombosis/ hemorrhage.

- Glucocorticoid therapy should be promptly initiated when AD is suspected.

- Mineralocorticoid replacement must be started when there is confirmed aldosterone deficiency.

- Hypertension is a common feature of APS; in patients with APS and AD, replacement therapy with glucocorticoids and mineralocorticoids may jeopardize hypertension management.

\section{Background}

Primary adrenal insufficiency or Addison's disease (AD) is a potentially fatal condition if not diagnosed in time. Antiphospholipid syndrome (APS) is a systemic autoimmune disorder characterized by recurrent arterial/venous thrombotic events due to complex interactions between antiphospholipid antibodies, endothelium and platelets. It occurs as a primary condition or in the presence of systemic lupus erythematosus or other systemic autoimmune diseases (1). AD is a rare APS complication (0.4\% of APS cases (2)), although it is the most common endocrine manifestation of the syndrome (3). Conversely, APS is diagnosed in less than $0.5 \%$ of all patients with $\mathrm{AD}(4)$.

Espinosa et al. (5) described 86 patients with APS and $\mathrm{AD}$ - in about one-third of the patients, adrenal 
insufficiency was the first clinical manifestation of APS. Abdominal pain and hypotension were the most frequently referred manifestations, followed by fever, nausea or vomiting, fatigue and altered mental status. Adrenal imaging shows hemorrhage in most cases (5). The pathophysiology behind the adrenal hemorrhage is not completely clear. The limited venous drainage of the glands, associated with a rich arterial supply, may cause local blood stasis and predispose to thrombosis, often followed by hemorrhagic infarction. Other presumed mechanisms include the development of adrenal hemorrhage following surgery or anticoagulant therapy (3). Another etiological explanation is based on the accumulation of late endosomes in the adrenal cells, which are important organelles participating in cholesterol trafficking and protein sorting within cells and that express epitopes recognized by antiphospholipid antibodies (aPL) (6).

Here, we describe a case of $\mathrm{AD}$ due to adrenal hemorrhage in a female patient with APS.

\section{Case presentation}

We present the case of a 36-year-old Caucasian woman with APS diagnosis since the age of 24 years. She had arterial hypertension and history of multiple thrombotic events: deep vein thrombosis, three spontaneous abortions, splenic vein thrombosis with consequent hypersplenism and thrombocytopenia. She had been hospitalized for acute renal failure (creatinine: $3.63 \mathrm{mg} /$ dL) after her third spontaneous abortion. At that time abdominal CT showed a heterogeneous nodular lesion in the right adrenal gland with high spontaneous density, suggestive of hematoma $(72 \times 50 \mathrm{~mm})$, a poorly visualized left adrenal gland and marked splenomegaly (Fig. 1).

Due to the renal failure and suspected autoimmune kidney involvement, she was discharged under glucocorticoid therapy (prednisolone: $1 \mathrm{mg} / \mathrm{kg} /$ day) with progressive dose reduction.

One month after being hospitalized and 1 week after stopping prednisolone, she was admitted to the emergency room (ER) presenting with 4 days of nausea, persistent vomiting and progressive asthenia. She was medicated at that time with warfarin: $5 \mathrm{mg} /$ day, pantoprazole: $40 \mathrm{mg} /$ day, nifedipine: $30 \mathrm{mg} /$ day and furosemide: $40 \mathrm{mg} /$ day. Being usually prone to hypertension, she was normotensive at the time, with blood pressure 110/81 $\mathrm{mmHg}$.

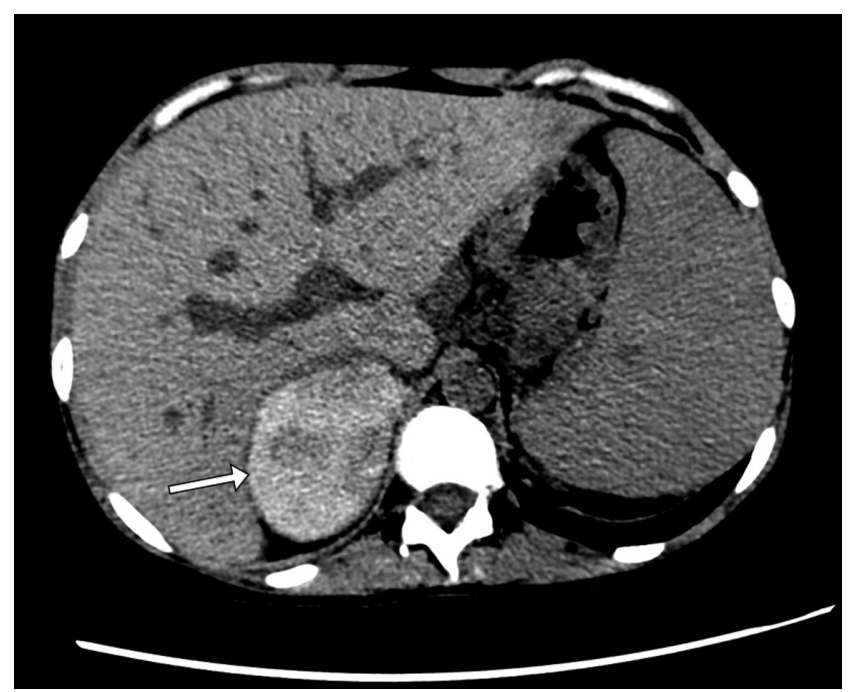

Figure 1

Unenhanced CT axial section demonstrating a heterogeneous right adrenal lesion (arrow) suggestive of adrenal hematoma with recent hemorrhage.

\section{Investigation and treatment}

The analytical study performed in the ER revealed hyponatremia $(114 \mathrm{mmol} / \mathrm{L}$, reference range $(\mathrm{RR})$ : 136-146), hyperkalemia $(7.9 \mathrm{mmol} / \mathrm{L}, \mathrm{RR}: 3.5-5.1)$ and significant worsening of renal function (creatinine: $4.90 \mathrm{mg} / \mathrm{dL}$, RR: 0.55-1.02). She was readmitted and restarted on therapy with prednisolone. Based on clinical presentation, adrenal insufficiency was suspected. Basal adrenal function tests under prednisolone $40 \mathrm{mg} / \mathrm{day}$ revealed morning serum cortisol $1.3 \mu \mathrm{g} / \mathrm{dL}$ (RR: 5-25) and ACTH $15 \mathrm{pg} / \mathrm{mL}$ (RR: 9-52). A probable diagnosis of primary adrenal failure was assumed. The patient initiated oral glucocorticoid replacement therapy (hydrocortisone: $10 \mathrm{mg}$ at wake time, $5 \mathrm{mg}$ at lunch and $5 \mathrm{mg}$ in the afternoon), with good clinical and analytical response. She reported improvement in energy levels and no nausea or vomiting.

Further study at the Department of Endocrinology, performed after clinical stabilization and withdrawing hydrocortisone for $24 \mathrm{~h}$, revealed morning serum cortisol: $<1 \mu \mathrm{g} / \mathrm{dL}$ (RR: $5-25$ ) and ACTH: $138 \mathrm{pg} / \mathrm{mL}$ (RR: 9-52), leading to diagnostic confirmation. Aldosterone and adrenal androgens levels were low; anti-21hydroxylase antibodies were negative; thyroid function was normal and there were no anterior pituitary deficits (Table 1). Mineralocorticoid replacement therapy with fludrocortisone $0.05 \mathrm{mg} /$ day was started. Screening for infectious diseases (including tuberculosis and human 
Table 1 Biochemical evaluation.

\begin{tabular}{|c|c|c|}
\hline Parameter & Result & $\begin{array}{c}\text { Reference } \\
\text { range }\end{array}$ \\
\hline Cortisol (8 AM) & $<1 \mu \mathrm{g} / \mathrm{dL}$ & $5-25$ \\
\hline ACTH (8 AM) & $138 \mathrm{pg} / \mathrm{mL}$ & $9-52$ \\
\hline Aldosterone & $<7.0 \mathrm{pg} / \mathrm{mL}$ & $40-310$ \\
\hline Active renin & $4.9 \mu \mathrm{U} / \mathrm{mL}$ & $7-76$ \\
\hline DHEA-SO4 & $<0.2 \mu \mathrm{g} / \mathrm{mL}$ & $0.35-4.3$ \\
\hline Androstenedione & $<0.3 \mathrm{ng} / \mathrm{mL}$ & $0.5-3.4$ \\
\hline 17-OHP & $1.70 \mathrm{ng} / \mathrm{mL}$ & $0.2-1.8$ \\
\hline 21-Hydroxylase antibodies & Negative & \\
\hline TSH & $2.4 \mathrm{pg} / \mathrm{mL}$ & $0.4-4.0$ \\
\hline FT4 & $3.0 \mathrm{pg} / \mathrm{mL}$ & $0.8-1.9$ \\
\hline Thyroglobulin antibodies & $<10 \mathrm{IU} / \mathrm{mL}$ & $<40$ \\
\hline $\begin{array}{l}\text { Thyroid peroxidase } \\
\text { antibodies }\end{array}$ & $<20 \mathrm{IU} / \mathrm{mL}$ & $<40$ \\
\hline Prolactin & $15 \mathrm{ng} / \mathrm{mL}$ & $<20$ \\
\hline $\mathrm{LH}$ & $1.6 \mathrm{mlU} / \mathrm{mL}$ & $<12$ \\
\hline FSH & $4.4 \mathrm{mlU} / \mathrm{mL}$ & $<9.6$ \\
\hline Creatinine & $1.68 \mathrm{mg} / \mathrm{dL}$ & $0.55-1.02$ \\
\hline Sodium & $141 \mathrm{mmol} / \mathrm{L}$ & $136-146$ \\
\hline Potassium & $4.2 \mathrm{mmol} / \mathrm{L}$ & $3.5-5.1$ \\
\hline Osmolality & $288 \mathrm{mosmol} / \mathrm{kg}$ & $260-302$ \\
\hline
\end{tabular}

17-OHP, 17-hydroxyprogesterone; ACTH, adrenocorticotropic hormone; DHEA-SO4, dehydroepiandrosterone sulfate; $\mathrm{FSH}$, follicle-stimulating hormone; FT4, free thyroxine; LH, luteinizing hormone; TSH, thyroidstimulating hormone.

immunodeficiency virus) was negative. Her drug history did not reveal any drugs with adrenolytic potential.

\section{Outcome and follow-up}

The patient was discharged from the Endocrinology Department with glucocorticoid (hydrocortisone: $10 \mathrm{mg}$ at wake time, $5 \mathrm{mg}$ at lunch and $5 \mathrm{mg}$ in the afternoon) and mineralocorticoid (fludrocortisone: $0.05 \mathrm{mg}$ at wake time) replacement therapy. Before discharge, education about hydrocortisone dose adjustment in sick days was ensured and a patient's steroid treatment card was given.

During follow-up, patient's renal function suffered progressive worsening until end-stage renal failure. Adjustment of antihypertensive medications was also necessary. She is currently under renal replacement therapy (peritoneal dialysis) awaiting renal transplantation.

Seven years after the AD diagnosis confirmation, the patient is presently treated with oral hydrocortisone (15 mg at wake time, $10 \mathrm{mg}$ at lunch and $5 \mathrm{mg}$ in the afternoon), oral fludrocortisone: $0.05 \mathrm{mg} /$ day, warfarin: $5 \mathrm{mg}$ with dose adjustments following INR measurements, and antihypertensive drugs, namely furosemide: $80 \mathrm{mg} /$ day, nifedipine: $60 \mathrm{mg} /$ day and bisoprolol: $2.5 \mathrm{mg} /$ day. The patient maintains regular follow-up in the Endocrinology outpatient clinic. She and her husband adopted a child.

\section{Discussion}

Primary adrenal insufficiency (PAI) or AD is a severe and potentially life-threatening condition characterized by the inability of adrenal cortex to produce glucocorticoids and/ or mineralocorticoids (7). The most common etiology of $\mathrm{AD}$ is autoimmune adrenalitis (8). In the presented case, antibodies against 21-hydroxylase were absent. Other causes of PAI include metastatic malignancy, infectious or infiltrative disorders, adrenoleukodystrophy or congenital adrenal hyperplasia. APS and consequent hemorrhage/ infarction of the glands, as in the case presented, is an uncommon cause, even though the adrenals are the endocrine glands most frequently involved in APS. Imaging performed in this patient showed hemorrhage/ hematoma, consistent with most cases described in the literature (5). Given the rarity of this complication and the non-specific character of the presentation, a high index of suspicion is needed. Therefore, if a patient with APS presents with abdominal complaints, weakness or asthenia, an initial evaluation of blood pressure and serum sodium/potassium should be immediately performed. Clinical suspicion should always motivate appropriate screening and confirmation tests, and treatment should promptly be initiated. Conversely, the possibility of APS should be raised in patients with AD of unknown etiology, after exclusion of more common causes, and even in the absence of previous history of thromboembolic disorders. Screening for lupus anticoagulant and anticardiolipin antibodies should be considered in all cases of adrenal hemorrhage or infarction (5).

Regarding AD management, glucocorticoid therapy should be initiated in all AD patients. After aldosterone deficiency confirmation, mineralocorticoid replacement with fludrocortisone must also be started. Considering APS patients' specific characteristics, arterial hypertension management can be particularly challenging. Indeed, hypertension is frequently found in patients with APS due to renal and reno-vascular pathology (thrombotic microangiopathy) (9). In $\mathrm{AD}$ patients who develop hypertension while receiving fludrocortisone, international guidelines suggest first reducing the dose of fludrocortisone, and if blood pressure remains uncontrolled, initiating antihypertensive treatment while continuing fludrocortisone (7). Finding this balance may become difficult with aggravating renal function, as occurred with the patient presented.

This clinical case highlights the importance of systematic screening procedures in all patients with APS and manifestations suggestive of $\mathrm{AD}$ and, on the other 
hand, the evaluation of APS specific autoantibodies in patients with adrenal infarction or hemorrhage.

\section{Declaration of interest}

The authors declare that there is no conflict of interest that could be perceived as prejudicing the impartiality of this case report.

\section{Funding}

This research did not receive any specific grant from any funding agency in the public, commercial or not-for-profit sector.

\section{Patient consent}

Written informed consent has been obtained from the patient for publication of the submitted article and accompanying images.

\section{Author contribution statement}

$\mathrm{D} O$ and $\mathrm{M} V$ drafted the manuscript, conducted the literature review and contributed equally to this work. M M, S P and F C critically revised the manuscript.

\section{References}

1 Negrini S, Pappalardo F, Murdaca G, Indiveri F \& Puppo F. The antiphospholipid syndrome: from pathophysiology to treatment. Clinical and Experimental Medicine 201717 257-267. (https://doi. org/10.1007/s10238-016-0430-5)
2 Cervera R, Boffa MC, Khamashta MA \& Hughes GR. The EuroPhospholipid project: epidemiology of the antiphospholipid syndrome in Europe. Lupus 200918 889-893. (https://doi. org/10.1177/0961203309106832)

3 Uthman I, Salti I \& Khamashta M. Endocrinologic manifestations of the antiphospholipid syndrome. Lupus 200615 485-489. (https:// doi.org/10.1191/0961203306lu2318rr)

4 Presotto F, Fornasini F, Betterle C, Federspil G \& Rossato M. Acute adrenal failure as the heralding symptom of primary antiphospholipid syndrome: report of a case and review of the literature. European Journal of Endocrinology 2005153 507-514. (https://doi.org/10.1530/eje.1.02002)

5 Espinosa G, Santos E, Cervera R, Piette JC, de la Red G, Gil V, Font J, Couch R, Ingelmo M \& Asherson RA. Adrenal involvement in the antiphospholipid syndrome: clinical and immunologic characteristics of 86 patients. Medicine 200382 106-118. (https://doi. org/10.1097/00005792-200303000-00005)

6 Berneis K, Buitrago-Tellez C, Muller B, Keller U \& Tsakiris DA. Antiphospholipid syndrome and endocrine damage: why bilateral adrenal thrombosis? European Journal of Haematology $2003 \mathbf{7 1}$ 299-302. (https://doi.org/10.1034/j.1600-0609.2003.00145.x)

7 Bornstein SR, Allolio B, Arlt W, Barthel A, Don-Wauchope A, Hammer GD, Husebye ES, Merke DP, Murad MH, Stratakis CA, et al. Diagnosis and treatment of primary adrenal insufficiency: An endocrine society clinical practice guideline. Journal of Clinical Endocrinology and Metabolism 2016101 364-389. (https://doi. org/10.1210/jc.2015-1710)

8 Betterle C, Dal Pra C, Mantero F \& Zanchetta R. Autoimmune adrenal insufficiency and autoimmune polyendocrine syndromes: autoantibodies, autoantigens, and their applicability in diagnosis and disease prediction. Endocrine Reviews 200223 327-364. (https:// doi.org/10.1210/edrv.23.3.0466)

9 Sangle SR, D'Cruz DP, Jan W, Karim MY, Khamashta MA, Abbs IC \& Hughes GR. Renal artery stenosis in the antiphospholipid (Hughes) syndrome and hypertension. Annals of the Rheumatic Diseases 2003 62 999-1002. (https://doi.org/10.1136/ard.62.10.999)

Received in final form 15 October 2018

Accepted 30 October 2018 